\title{
Acomodação dialetal de sergipanos em São Paulo: a influência das redes sociais e do indivíduo
}

\author{
Amanda de Lima Santana \\ Universidade de São Paulo (USP), São Paulo, São Paulo, Brasil \\ amanda.santana@usp.br \\ https://orcid.org/0000-0002-8047-100X
}

DOI: http://dx.doi.org/10.21165/el.v47i1.1931

\begin{abstract}
Resumo
Este artigo apresenta análises preliminares sobre a pronúncia de vogais médias pretônicas /e/ e /o/ (como em "relógio" e "coragem") na fala de sergipanos residentes na região metropolitana de São Paulo, com o intuito de mostrar seus graus de acomodação dialetal, a partir dos aportes teóricos da Sociolinguística Variacionista (LABOV, 2008 [1972]), do conceito de redes sociais (MILROY, 1987 [1980]; MILROY; LLAMAS, 2013 [2002]) e dos fundamentos da terceira onda da Sociolinguística (ECKERT, 2012). Até o momento, os testes estatísticos indicam que a configuração da rede do migrante não importa tanto quanto suas características individuais, no processo de acomodação dialetal.
\end{abstract}

Palavras-chave: Acomodação dialetal; vogais médias pretônicas; Sergipe.

Dialectal accommodation of Sergipanos in São Paulo: the influence of the social networks and the individual

\begin{abstract}
This article presents preliminary analyses of the pronunciation of the mid vowels /e/ and /o/ in pretonic position, as in "relógio" (clock) and "coragem" (courage), in the speech of Northeastern Brazilians from Sergipe residing in the metropolitan region of São Paulo. This work aims to show the degree of dialectal accommodation in this population from the theoretical contributions of the Variationist Sociolinguistics (LABOV, 2008 [1972]), the concept of social networks (MILROY, 1987 [1980]; MILROY; LLAMAS, 2013 [2002]) and the fundamentals of the third wave of the sociolinguistics (ECKERT, 2012). Thus far, the statistical tests showed that the speaker's network configuration is not as decisive as the individual characteristics in the process of dialectal accommodation.
\end{abstract}

Keywords: Dialectal accommodation; mid vowels in pretonic position; Sergipe.

\section{Introdução}

Baseando-se no conceito de redes sociais (MILROY, 1987 [1980]; MILROY; LLAMAS, 2013 [2002]), nos fundamentos da terceira onda da Sociolinguística (ECKERT, 2012) e nos aportes teórico-metodológicos da Sociolinguística Variacionista (LABOV, 2008 [1972]), esta pesquisa propõe investigar os graus de acomodação dialetal (TRUDGILL, 1986) no português falado por sergipanos residentes na região metropolitana de São Paulo. A análise da realização variável das vogais médias pretônicas /e/ e /o/ (como em "negócio" e "colégio") objetiva verificar se esses sergipanos passaram a pronunciar, mais frequentemente, tais vogais com menor grau de abertura, diferenciando-se do padrão característico dos falares do Nordeste (NASCENTES, 1953 
[1922]). A partir de uma amostra coletada de acordo com a dinâmica das redes sociais, interessa averiguar se o contato maior entre os migrantes com paulistanos (e paulistas) de um lado e com sergipanos (e outros nordestinos), por outro, interfere diferentemente na acomodação dialetal. O estudo se propõe a dar destaque para a interação social dos migrantes, antes de categorizá-los a priori de acordo com categorias macrossociais (como sexo/gênero, idade e classe social).

\section{Pressupostos teórico-metodológicos}

A pesquisa se encaixa no modelo teórico da sociolinguística quantitativa, lida com o conceito de redes sociais (MILROY, 1987 [1980]; MILROY; LLAMAS, 2013) e trabalha com a noção de identidade (ECKERT, 2012). A teoria laboviana (LABOV, 2008 [1972], 2001) afasta-se da tradição linguística que concebia a língua como um sistema homogêneo, na medida em que a define a partir da concepção de heterogeneidade inerente e regulada. Assim, a mudança linguística é vista como um processo que tem correlações com os aspectos sociais de uma comunidade. Diferentemente da concepção saussuriana, portanto, Labov (2008[1972]) esclarece que não há como estudar a língua fora de seu aspecto social e é por conta dessa visão que ele evitou, pelo menos por algum tempo, o próprio termo "sociolinguística". Nesse estudo da pronúncia de vogais pretônicas por sergipanos estabelecidos em São Paulo, a variação é analisada em conjunto com a variabilidade social, que por sua vez é essencial para compreender as diferenças nos modos de falar dos indivíduos. Ademais, nos estudos tipicamente variacionistas, "para desvelar tanto a estrutura linguística quanto a estrutura social, [deve-se], necessariamente, coletar grande quantidade de dados" (GUY, 2007, p. 19), etapa essa que também foi realizada neste estudo, pois, como se verá mais adiante, um grande número de ocorrências de vogais pretônicas está sendo analisado para compreender o processo da acomodação dialetal.

Embora a pesquisa parta de premissas essencialmente labovianas, o método proposto por Labov para analisar tal relação não se mostra como o mais adequado para o estudo da acomodação dialetal de migrantes. Tipicamente, os trabalhos sociolinguísticos lidam com corpora construídos a partir de categorias censitárias, como sexo/gênero, faixa etária, escolaridade e classe social, de modo que se busque um número equilibrado de entrevistas com homens e mulheres, mais pobres e mais ricos, mais jovens e mais velhos, e assim por diante. Tal método se justifica na medida em que se buscam padrões gerais na fala de uma comunidade. Em pesquisas sobre acomodação dialetal, a construção de uma amostra aleatória pode não ser o mais apropriado, uma vez que para compreender esse processo faz sentido observar com quem os migrantes estão conversando, já que eles estão se acomodando justamente ao que estão ouvindo. Nesse sentido, o método das redes sociais pode ser mais eficiente.

É essencial dizer ainda que o conceito de "acomodação dialetal" utilizado no presente estudo se aproxima mais daquele desenvolvido por Trudgill (1986). Tal autor define a acomodação de longo prazo (em contraposição à de curto prazo) como a que ocorre entre indivíduos de diferentes variedades regionais. Trudgill esclarece que, nas pesquisas que levam em conta esse tipo de acomodação, três pontos são colocados como norteadores, a saber: (i) determinar como os falantes se acomodam; (ii) em que medida eles se acomodam; (iii) e por que algumas situações e alguns indivíduos produzem mais (ou tipos diferentes de) acomodação do que outros. As perguntas (ii) e (iii), de fato, são 
de interesse para esta pesquisa com os sergipanos migrantes, posto que quer se buscar em que medida eles estão se acomodando à fala paulistana e compreender melhor o motivo de alguns indivíduos se acomodarem mais do que outros, caso os dados apontem realmente para esse direcionamento.

O corpus de 27 falantes é composto por duas redes sociais distintas, formadas a partir de um informante âncora (ou ponto de partida), que indicou, depois de realizada a entrevista sociolinguística, as dez pessoas com quem mais interage no cotidiano. Dessas indicadas, as sergipanas também foram entrevistadas, enquanto as outras foram apenas "anotadas", para se ter o controle de suas origens. Com esse procedimento, criaram-se duas redes sociais, com o intuito de "monitorar" quem conversa com quem. Tal mapeamento serviu para avaliar individualmente os sujeitos da amostra, verificando se a configuração das redes (maior ou menor quantidade de sujeitos sergipanos/nordestinos) influencia ou não os graus de acomodação da fala desses sergipanos migrantes.

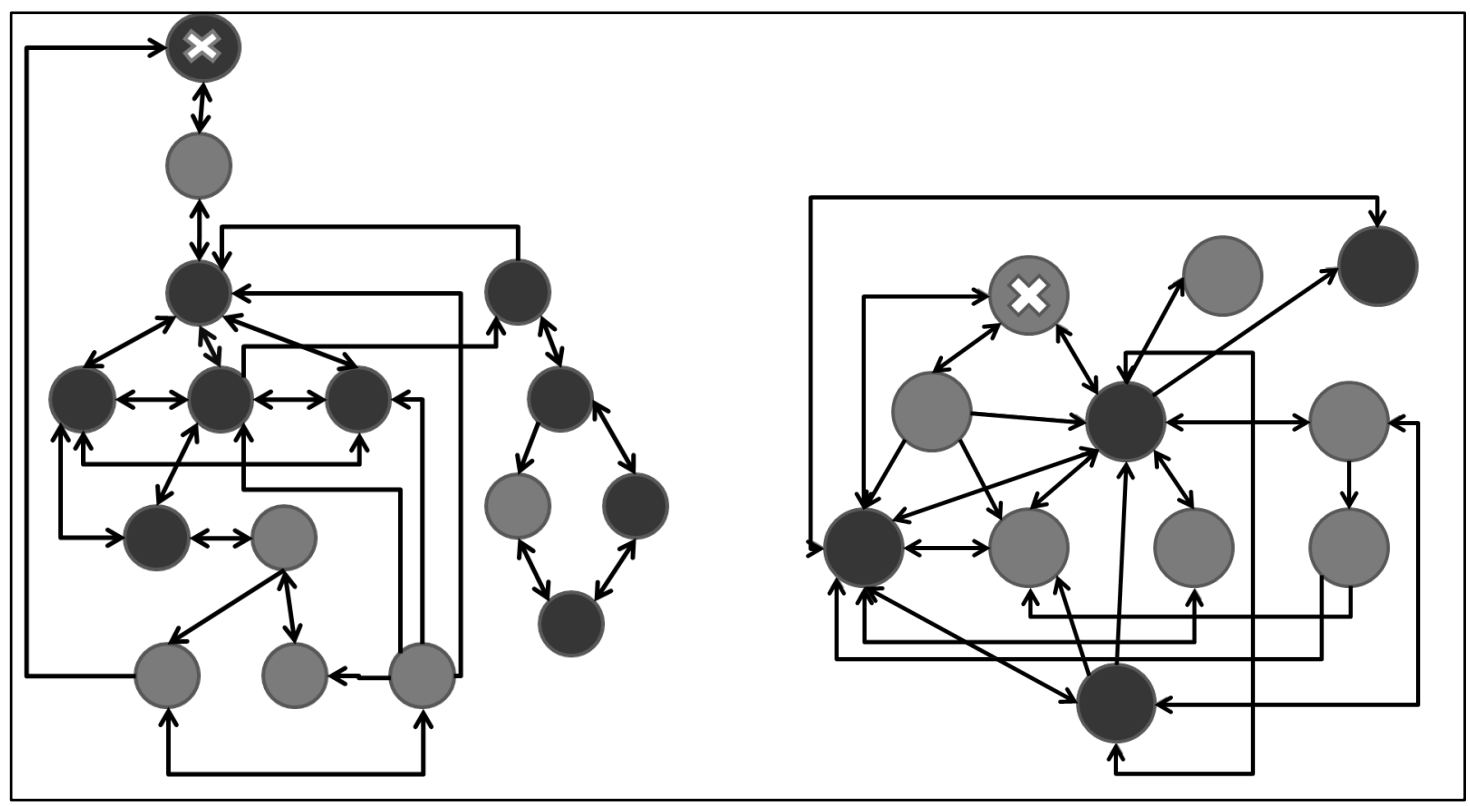

Figura 1: Esquema gráfico das redes (rede 1 à esquerda e rede 2 à direita)

A Figura 1 representa as redes sociais dos migrantes cuja fala foi coletada. Cada círculo representa um informante; a cor cinza escura representa as mulheres e a cor cinza mais clara os homens. Os âncoras estão marcados pelo X no interior do círculo. Percebese que a rede 1 é formada por 16 indivíduos, enquanto a 2 é composta por 11 . As flechas com duas pontas significam que um informante $\mathrm{A}$ indicou $\mathrm{B}$ e $\mathrm{B}$ também indicou A (ou seja, uma "dupla indicação") e as flechas com apenas uma ponta significam que A indicou B, mas B não indicou A como uma das pessoas com quem mais tem contato. Observa-se que alguns indivíduos recebem muitas flechas, indicando, portanto, uma intensa conexão entre eles com o resto da rede. Vê-se, por exemplo, o caso da rede 2: a mulher que está representada pelo círculo cinza escuro central da figura parece ser alguém que estabelece contato com a grande maioria dos indivíduos da rede. Posteriormente, será analisada a possível relação entre esse número alto de interações com o processo de acomodação dialetal, ou seja, a pesquisa buscará verificar se é verdadeira a hipótese de que tal informante apresenta menores taxas de acomodação por ter um grau alto de interação com sergipanos. 
A maioria dos migrantes da rede 1 faz parte de uma mesma família: irmãos, primos e casais. Vários deles moram no mesmo bairro e pouco saem de lá, o que permite caracterizá-la como fechada (BORTONI-RICARDO, 2011 [1985]), já que eles têm menos contato com paulistas/paulistanos quando comparados aos integrantes da rede 2 . Há, em tal rede, donas de casa e aposentados, por exemplo, que ficam bastante tempo em casa. Seus contatos mais frequentes, então, são seus próprios familiares (sergipanos, na maioria das vezes) e vizinhos (majoritariamente nordestinos).

Os integrantes da rede 2, por outro lado, e apesar de a maioria também residir no mesmo bairro, têm uma mobilidade geográfica maior, justamente por sair mais e visitar outros lugares. A rede é formada, entre outros indivíduos, por uma professora que mora em Osasco e trabalha em Barueri (cidades vizinhas na Grande São Paulo) e por um taxista que circula muito pela cidade, pouco ficando em casa. Percebe-se que esses migrantes, em relação aos da rede 1, têm mais contato com paulistas/paulistanos.

A partir de tal caracterização, aventou-se a hipótese de que os migrantes da rede 1, por terem menos contato com paulistas/paulistanos, apresentam taxas de acomodação à fala paulistana menores do que os integrantes da rede 2. Isto é, parte-se da premissa de que a configuração das redes pode influenciar as taxas de acomodação de seus integrantes. No entanto, não se descarta a possibilidade de as particularidades de cada indivíduo serem importantes no processo de acomodação dialetal, ou seja, pode haver o caso de um migrante que pertence à rede mais fechada ter taxas maiores de acomodação. O objetivo da pesquisa, então, é verificar se o que importa mais é a rede ou o indivíduo em tal processo.

Com vistas a comparar os dados de fala dos migrantes sergipanos, a pesquisa faz uso de duas amostras controle, para que se tenha uma visão mais clara do quanto os indivíduos estão se acomodando ou não ao falar paulistano. A primeira delas é a SP2010 ${ }^{1}$ (MENDES; OUSHIRO, 2012), construída entre 2011 e 2013, com o objetivo de colaborar para a disseminação de trabalhos sociolinguísticos sobre a variedade de fala paulistana. Tal banco de dados é constituído de 60 entrevistas sociolinguísticas, realizadas com homens e mulheres, pertencentes a três faixas etárias (dos 19 aos 34 anos, dos 35 aos 59 e 60 anos ou mais), com diferentes níveis de escolaridade e residentes de zonas variadas da cidade. Para a presente pesquisa, apenas as entrevistas de 7 informantes foram selecionadas, pois tais dados já haviam sido extraídos por Oushiro (2016), para o desenvolvimento de sua pesquisa de pós-doutorado.

A segunda amostra controle utilizada pertence ao banco de dados "Falares Sergipanos" (FREITAG, 2013), que é formado por diversos tipos de entrevistas, realizadas com diferentes tipos de grupo de informantes (religiosos e universitários, por exemplo). As quatro entrevistas utilizadas para esta pesquisa são de habitantes de um pequeno povoado chamado Açuzinho (localizado a 75 quilômetros da capital Aracaju), cujos perfis mais se aproximavam daqueles dos migrantes aqui analisados (pouca escolarização). Nos gráficos e nas tabelas que aparecem a seguir, tal amostra é identificada como SE-2012. ${ }^{2}$

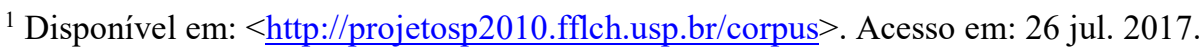

${ }^{2} \mathrm{~A}$ amostra dos migrantes sergipanos é identificada como SESP-2016.
} 
É essencial esclarecer ainda o envelope de variação utilizado na realização do estudo. Como o intuito central dessa pesquisa é verificar se está ocorrendo acomodação na fala de sergipanos em São Paulo em direção à pronúncia paulistana, decidiu-se analisar apenas aquelas palavras em que mais há favorecimento ao abaixamento da vogal, pois há contextos, na variedade sergipana, nos quais os falantes podem alçar a vogal pretônica (como no caso de "menino") ou realizá-la como média (em "depois", por exemplo). De acordo com Mota (1979), favorecem o abaixamento da vogal pretônica: vogal baixa /a, $\varepsilon$, / na sílaba contígua à pretônica (como em "memória" e "coragem"); uma vogal nasal que não seja alta (como em "dezembro"); a presença da fricativa velar/x/ em coda silábica ou no ataque ${ }^{3}$ (como em "mercado" e "relógio"). Além disso, evitou-se incluir palavras em que a média pretônica ocorria em casos de ditongo, por conta da dificuldade de se segmentar as vogais nesses casos, já que é difícil verificar onde uma vogal termina e outra começa, tanto visualmente (olhando para a onda sonora) quanto de oitiva (como em "doação", por exemplo).

\section{Normalização de Lobanov}

O objeto linguístico dessa pesquisa são as vogais médias pretônicas, mais precisamente os valores dos formantes F1 (relacionados à altura da vogal) e F2 (relacionado ao eixo horizontal), extraídos a partir do programa Praat (BOERSMA; WEENINK, 2014). Trata-se, portanto, de uma variável numérica: quanto mais alto o valor de F1 (em Hz), mais baixa a vogal é.

Os valores de frequência de formantes, numa pesquisa como esta, devem ser normalizados porque o trato vocal de cada indivíduo tem efeito na produção dos segmentos fônicos. Na tentativa de minimizar possíveis enviesamentos, usa-se a normalização de Lobanov (1971), que é considerada pelos foneticistas como o melhor procedimento, de acordo com Barbosa e Madureira (2015, p. 269), que explicam que tal técnica

[...] altera os valores brutos das frequências de formantes para valores normalizados por $z$-score, que são relativos aos valores de média e de desvio padrão de todas as vogais de cada falante. $\mathrm{O} z$-score é a distância em relação à média em unidades de desvio padrão de todas as vogais de cada falante.

As médias normalizadas, portanto, mantêm os aspectos relacionais entre as vogais, de modo que se torna possível fazer comparações entre diferentes indivíduos e diferentes pronúncias.

\section{Resultados parciais}

A Figura 1 mostra a distribuição geral dos dados, das três amostras (migrantes, paulistanos e sergipanos que ainda residem em Sergipe). O gráfico da esquerda mostra as médias dos formantes sem passar pela normalização de Lobanov. Percebe-se que a variação é bem maior quando comparada com o gráfico de valores normalizados, à direita.

\footnotetext{
${ }^{3}$ No ataque da mesma sílaba a qual pertence a vogal pretônica ou o ataque da sílaba seguinte. No caso do ataque da sílaba seguinte, pode ocorrer um tepe (como em "coragem").
} 
No gráfico com dados não normalizados, a rede 1 apresenta valores maiores de F1 para as vogais /e/ e /o/ em relação às médias da rede 2, o que estaria de acordo com a hipótese aqui formulada: os sujeitos da rede 1 estariam menos acomodados e, portanto, apresentariam médias mais altas, por pertencerem a uma rede mais fechada. No entanto, com a normalização de Lobanov, esse padrão não se mantém, pois se observa que a variação entre as amostras fica bastante reduzida.

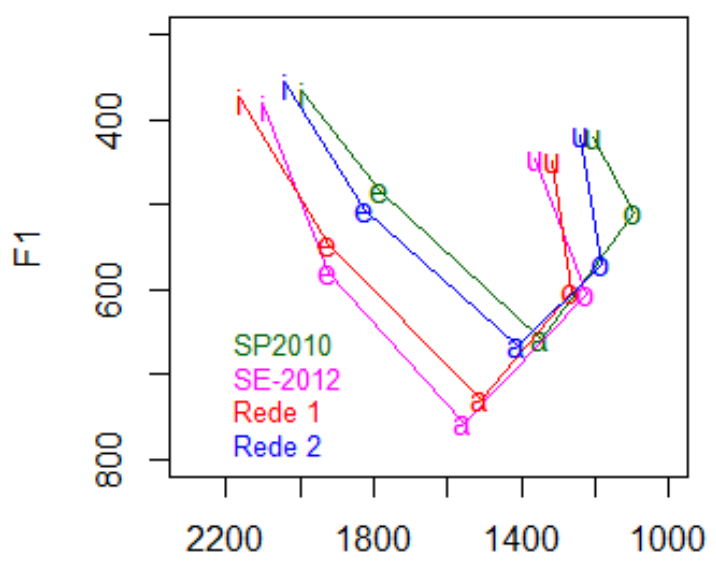

F2

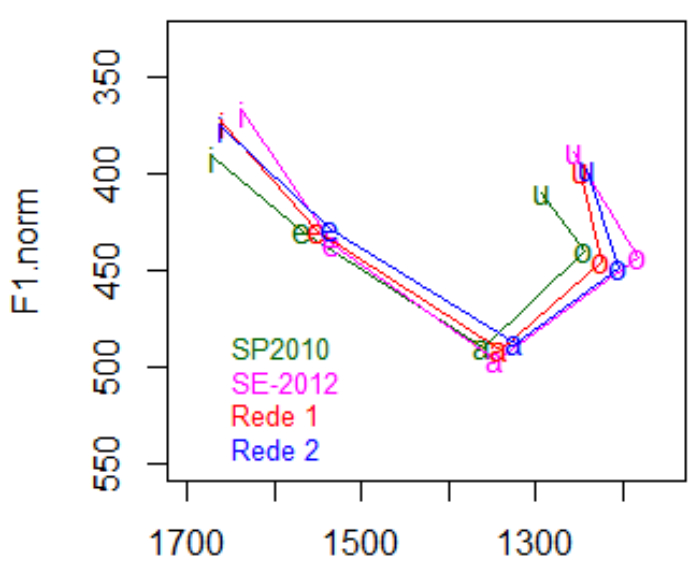

F2.norm

Figura 2: Médias de F1/F2 das vogais pretônicas das três amostras (não normalizadas à esquerda e normalizadas à direita)

Apenas visualmente, não é possível afirmar se as diferenças entre as amostras são significativas ou não. Por esse motivo, modelos de regressão linear foram rodados, na plataforma R (R CORE TEAM, 2017), para testar se tais diferenças são ou não significativas. A Tabela 1 apresenta os resultados do modelo de regressão linear para a vogal pretônica /e/.

Tabela 1: Estimativas (em Hz) de valores de F1 normalizados para vogal /e/ pretônica nas três amostras $(\mathrm{N}=4430)$

\begin{tabular}{lrrrr}
\hline & Estimativa & Erro padrão & Valor de $\boldsymbol{t}$ & Significância $(\boldsymbol{p})$ \\
\hline (Intercept) & 419,996 & 2,465 & 170,392 & $<2 \mathrm{e}-16^{* * *}$ \\
SE-2012 & 14,325 & 3,680 & 3,893 & $<0,001 * * *$ \\
SESP-2016 & 4,706 & 2,563 & 1,836 & $0,071$. \\
\hline
\end{tabular}

Modelo: lmer (F1.NORM AMOSTRA + (1|INFORMANTE) + (1|PALAVRA), data=VOGAL.e2)

A Tabela 1 apresenta, em sua primeira coluna, os níveis da variável independente (ou seja, as diferentes amostras); o valor de Intercept se refere ao nível de referência que, nesta análise, foi estabelecido como "SP2010". A segunda coluna apresenta as medidas estimadas para a variável dependente (valores de F1), em sua unidade de análise (Hz). Desse modo, a estimativa de valor médio de F1 da vogal/e/ para os paulistanos é de $419,996 \mathrm{~Hz}$. Os demais valores de estimativas devem ser lidos com referência ao intercept; para os sergipanos que não migraram (SE-2012), a estimativa de valor médio de F1 da vogal /e/ é 14,325 Hz acima da estimativa para os paulistanos, ou seja, 419,996 $+14,325=434,321 \mathrm{~Hz}$. Percebe-se que o valor de estimativa para os sergipanos migrantes (SESP-2016) é 4,706 Hz acima da estimativa dos paulistanos (424,702 Hz, portanto), o que indica uma aproximação à pronúncia paulistana e um distanciamento em relação ao falar sergipano. A última coluna traz o valor de significância (ou valor de $p$ ), "que mede 
a probabilidade de se observar tal distribuição em caso de a hipótese nula ser verdadeira; por convenção, estabelece-se um limite de até $5 \%(0,05)$ para que um resultado seja considerado significativo" (OUSHIRO, 2016, p. 42).

A Tabela 1 mostra, então, que o modelo de regressão linear calcula uma probabilidade acima do limite de 0,05 de que se tenham observado as medidas de 419,996 $\mathrm{Hz}$ para os paulistanos e de $424,702 \mathrm{~Hz}$ para os migrantes em caso de a hipótese nula ser verdadeira, ou seja, tal diferença não é significativa. Por outro lado, pode-se observar que a diferença entre as estimativas dos paulistanos e dos sergipanos não migrantes é significativa, uma vez que o valor de $p$ está abaixo de 0,05 .

Tabela 2: Estimativas (em Hz) de valores de F1 normalizados para vogal /o/ pretônica nas três amostras $(\mathrm{N}=\mathbf{2 6 9 4})$

\begin{tabular}{lrrrr}
\hline & Estimativa & Erro padrão & Valor de $\boldsymbol{t}$ & Significância (p) \\
\hline (Intercept $)$ & 431,006 & 3,431 & 125,628 & $<2 \mathrm{e}-16^{* * *}$ \\
SE-2012 & 6,975 & 5,578 & 1,250 & 0,218 \\
SESP-2016 & 10,514 & 3,693 & 2,847 & $0,007 * *$ \\
\hline
\end{tabular}

Modelo: lmer (F1.NORM AMOSTRA + (1|INFORMANTE) + (1|PALAVRA), data=VOGAL.o2 $)$

A Tabela 2, de modo semelhante à 1 , apresenta os resultados para a vogal /o/ e indica que a diferença de $10,514 \mathrm{~Hz}$ entre a estimativa dos paulistanos e a dos migrantes é significativa. Isto é, o valor de $p$, nesse caso, está abaixo de 0,05 e, portanto, é baixa a probabilidade de essa distribuição ser resultado de uma distribuição aleatória. Esses números indicam que, em relação à vogal posterior $/ \mathrm{o} /$, os migrantes não estão tão acomodados à fala paulistana, diferentemente do que foi visto com a vogal anterior /e/. Por outro lado, e surpreendentemente, o modelo mostra que não existe diferença significativa entre as estimativas dos paulistanos e as dos sergipanos que não migraram. Uma possível explicação para esse resultado é que poucos informantes da amostra sergipana foram incluídos na análise e, portanto, a fala sergipana não está sendo fielmente representada.

As Tabelas 1 e 2 serviram para mostrar as diferenças entre as amostras. O próximo passo é averiguar se as redes têm comportamentos diferentes em relação ao processo de acomodação.

Tabela 3: Estimativas (em Hz) de valores de F1 normalizados para vogal /e/ pretônica nas duas redes $(\mathrm{N}=\mathbf{3 7 1 7})$

\begin{tabular}{lcccc}
\hline & Estimativa & Erro padrão & Valor de $\boldsymbol{t}$ & Significância $(\boldsymbol{p})$ \\
\hline $\begin{array}{l}\text { Sem incluir SP2010 } \\
\text { (Intercept) }\end{array}$ & 423,699 & 1,698 & 249,586 & $<2 \mathrm{e}-16^{* * *}$ \\
Rede 2 & 0,927 & 2,204 & 0,421 & 0,678 \\
\hline Com a inclusão de SP2010 & & & \\
$($ Intercept $)$ & 392,163 & 4,214 & 93,063 & $<2 \mathrm{e}-16^{* * *}$ \\
Rede1 & 3,672 & 4,330 & 0,848 & 0,409 \\
Rede 2 & 2,678 & 4,421 & 0,606 & 0,553 \\
\hline Modelo: lmer (F1.NORM $\sim$ REDE + (1|INFORMANTE) + (1|PALAVRA), data = redes.e $)$
\end{tabular}

A Tabela 3 mostra que a diferença entre as estimativas da rede 1 (valor do intercept) e da rede 2 é muito pequena, para a vogal /e/, quando apenas as redes são comparadas entre si. O valor de significância ultrapassa os $5 \%$ (vê-se o valor de 0,678 na última coluna). Com a inclusão da amostra paulistana no modelo, percebe-se que ambas 
as redes estão acomodadas à fala paulistana, pois não há diferença significativa entre suas estimativas e a da amostra SP2010.

Tabela 4: Estimativas (em Hz) de valores de F1 normalizados para vogal /o/ pretônica nas duas redes $(\mathrm{N}=\mathbf{2 1 7 3})$

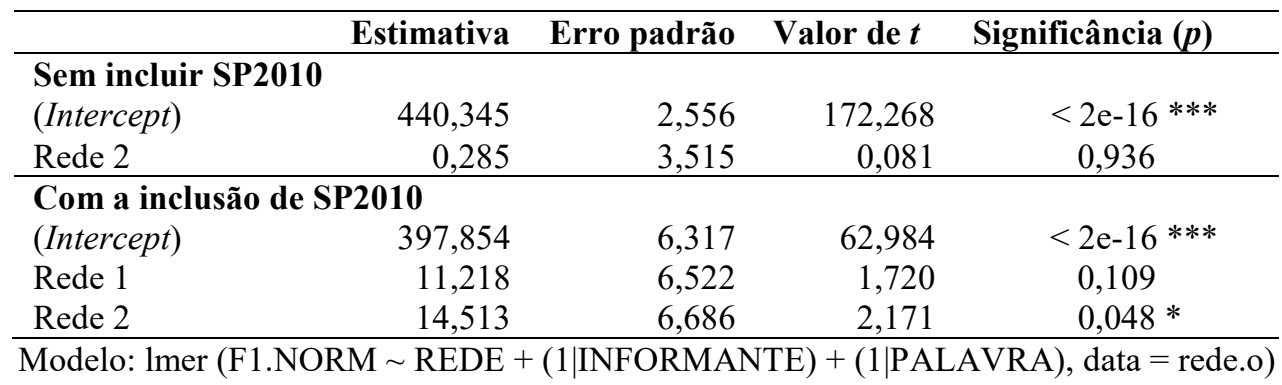

Em relação à vogal /o/, sem a inclusão dos dados de SP2010, a Tabela 4 mostra que não há diferença significativa entre a estimativa da rede 1 (intercept) e a da rede 2. Observa-se que o valor de $p$ está bastante acima de $0,05(0,936)$. No entanto, quando os valores são comparados com a estimativa dos paulistanos, percebe-se que os falantes da rede 2 não estão acomodados à fala paulistana. Os números corroboram justamente o oposto do que foi aventado, isto é, são os sujeitos da rede mais aberta que estão menos acomodados, pelo menos em relação à vogal /o/. Os valores de significância, assim, indicam que a configuração da rede não exerce influência na fala de seus sujeitos quando se analisa /e/, mas, por outro lado, faz diferença ser da rede 1 ou da rede 2 quando se observam os dados de /o/, pelo menos no caso desses sergipanos migrantes.

A partir do que foi visto com os modelos de regressão, a pergunta que se coloca agora é: há diferenças significativas entre os migrantes? Isto é, será que todos eles apresentam um mesmo padrão de variação ou certos falantes têm padrões mais diferentes do resto dos integrantes de sua rede? Por esses motivos, os quadros vocálicos individuais foram criados para visualizar as possíveis diferenças e semelhanças entre os sujeitos.

Os gráficos abaixo mostram o quadro vocálico de cada um dos informantes, separados por sexo e por rede. As figuras mostram que existe uma variabilidade na produção de tais vogais entre integrantes de uma mesma rede. Na Figura 3, por exemplo, no gráfico da direita, percebe-se que a vogal /o/ de JoanaT é a mais baixa entre as migrantes. 

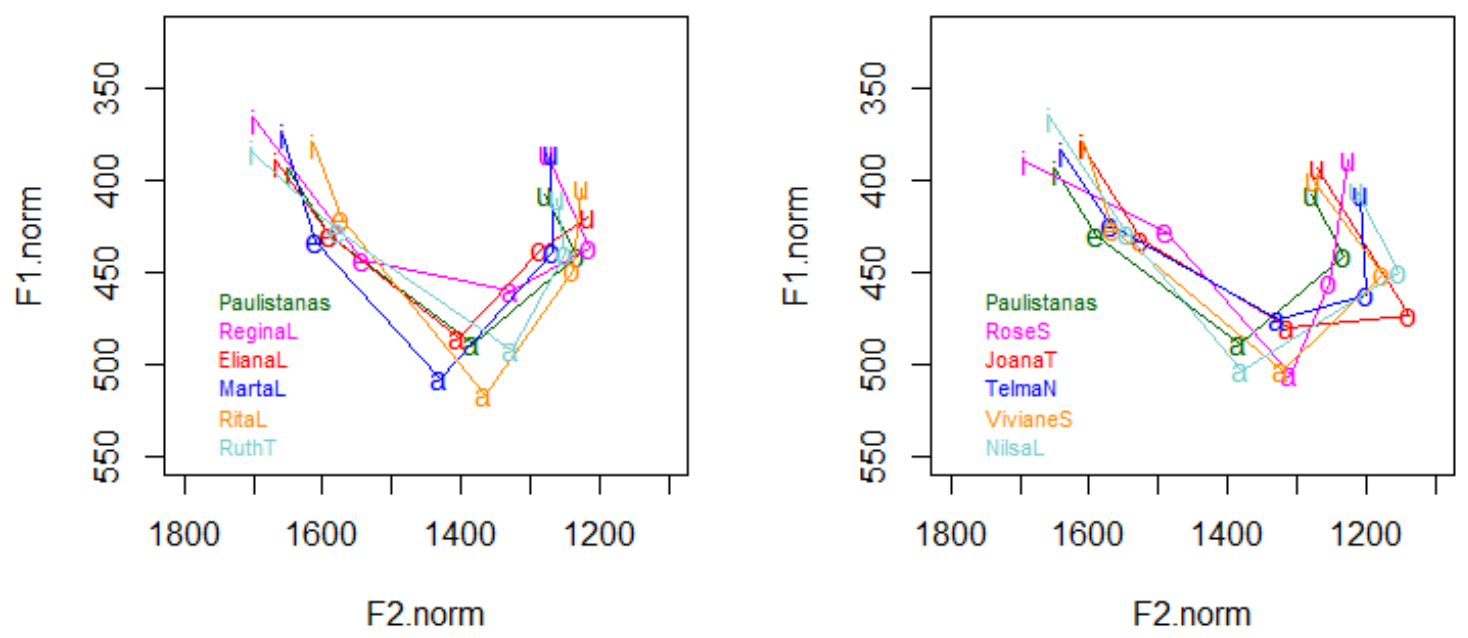

Figura 3: Médias normalizadas de F1/F2 das vogais pretônicas das mulheres da rede 1 em comparação com as paulistanas 4

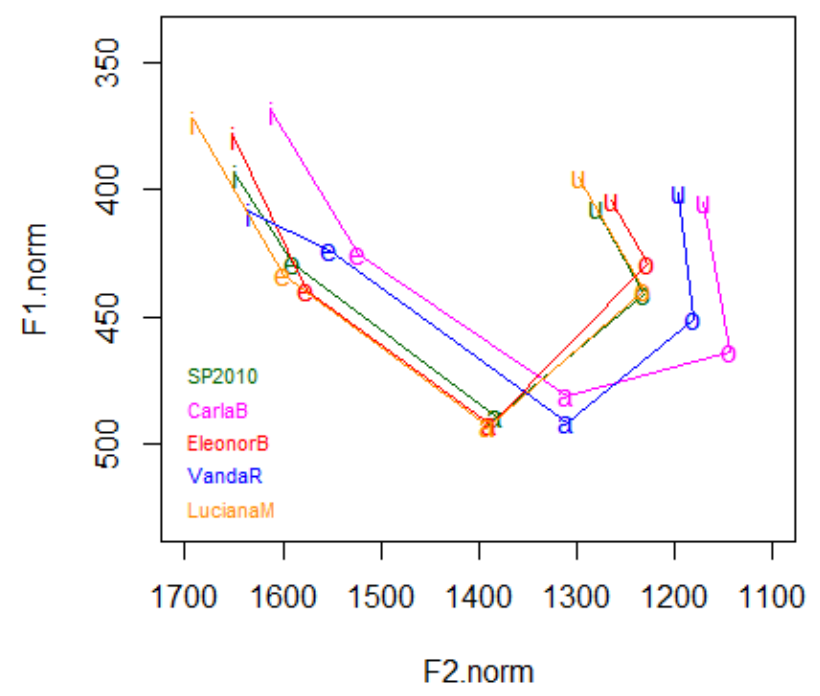

Figura 4: Médias normalizadas de F1/F2 das vogais pretônicas das mulheres da rede 2 em comparação com as paulistanas

$\mathrm{Na}$ Figura 4, CarlaB e VandaR apresentam valores médios de /e/ menores do que os das próprias paulistanas. EleonorB, por sua vez, é a que tem a média menos próxima da amostra SP2010. Em relação à /o/, vê-se que CarlaB é a que mais se distancia da média das paulistanas enquanto que EleonorB apresenta uma média ligeiramente mais baixa que a de SP2010.

\footnotetext{
${ }^{4}$ Os dois gráficos apresentam médias apenas das migrantes da rede 1 (além das paulistanas). Optou-se pela elaboração de dois gráficos, e não de apenas um, para que a visualização das linhas não ficasse comprometida.
} 

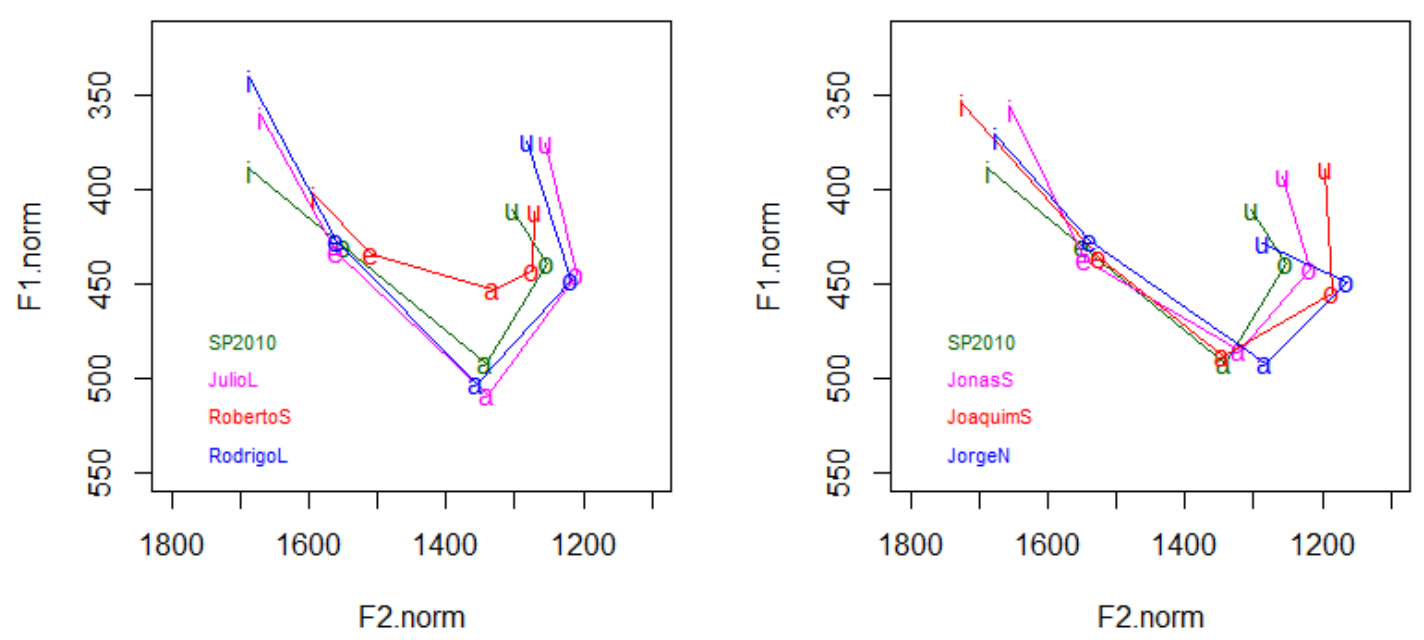

Figura 5: Médias normalizadas de F1/F2 das vogais pretônicas dos homens da rede 1 em comparação com os paulistanos

Em ambos os gráficos da Figura 5, é visível que a variação é maior em relação à vogal /o/ do que em relação à /e/. Todos os 6 migrantes da rede 1 apresentam médias muito próximas da média paulistana para /e/, mas esse quadro não se repete para a vogal /o/. JoaquimS, por exemplo, parece abrir /o/ com uma frequência maior do que os outros migrantes, o que indica que ele pouco se acomodou à fala paulistana, pelo menos no que se refere a essa variável linguística.
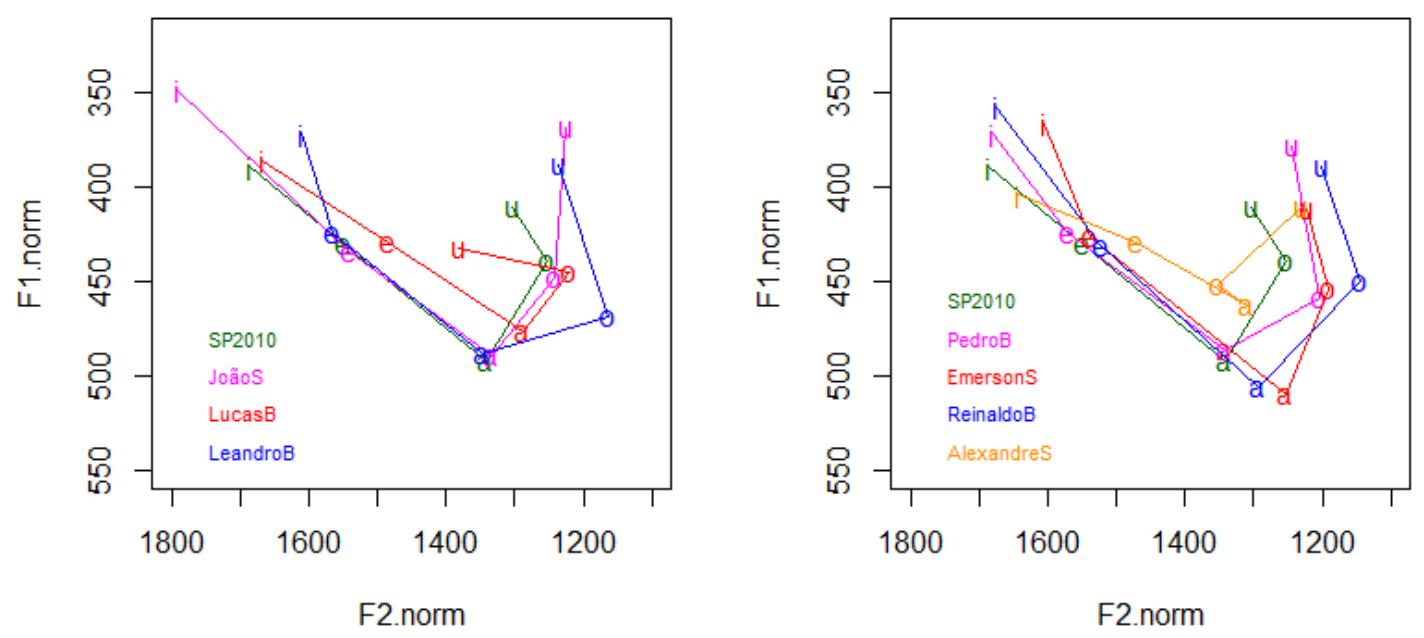

Figura 6: Médias normalizadas de F1/F2 das vogais pretônicas dos homens da rede 2 em comparação com os paulistanos

Percebemos que, dentre os informantes homens da rede 2 , o padrão é semelhante ao que visualizamos nos gráficos dos migrantes da rede 1, isto é, pouca diferença na altura de /e/ entre os informantes da amostra SESP-2016 e da SP2010 e maior variação no que concerne à vogal /o/. O informante LeandroB parece ser o que está menos acomodado à fala paulistana referente à vogal /o/.

Visualmente, não é possível afirmar se as diferenças observadas entre os migrantes são significativas ou não, por isso, modelos de regressão linear foram rodados 
no $\mathrm{R}$ para apurar tais estimativas. Para o presente artigo, apenas as estimativas dos homens, de ambas as redes, são apresentadas.

Tabela 5: Estimativas (em Hz) de valores de F1 normalizados para vogal /e/ pretônica dos homens da rede $1(\mathrm{~N}=977)$

\begin{tabular}{lrrrr}
\hline & Estimativa & Erro padrão & Valor de $\boldsymbol{t}$ & Significância $(\boldsymbol{p})$ \\
\hline (Intercept) & 430,416 & 2,3791 & 180,914 & $<2 \mathrm{e}-16^{* * *}$ \\
JoaquimS & 5,234 & 3,933 & 1,311 & 0,190 \\
JonasS & 7,070 & 3,771 & 1,874 & $0,061$. \\
JorgeN & $-3,624$ & 3,655 & $-0,992$ & 0,322 \\
JulioL & 2,436 & 4,085 & 0,596 & 0,551 \\
RobertoS & 3,393 & 4,143 & 0,819 & 0,413 \\
RodrigoL & $-0,670$ & 3,211 & $-0,218$ & 0,828 \\
\hline \multicolumn{5}{c}{ Modelo: lm (F1.NORM $\sim$ INFORMANTE, data $=$ h.1.SP.e) }
\end{tabular}

Tabela 6: Estimativas (em Hz) de valores de F1 normalizados para vogal /o/ pretônica dos homens da rede $1(N=647)$

\begin{tabular}{lrrrc}
\hline & Estimativa & Erro padrão & Valor de $\boldsymbol{t}$ & Significância $(\boldsymbol{p})$ \\
\hline (Intercept) & 439,108 & 2,414 & 181,869 & $<2 \mathrm{e}-16^{* * *}$ \\
JoaquimS & 15,201 & 5,512 & 2,758 & $0,006^{* *}$ \\
JonasS & 5,785 & 4,652 & 1,244 & 0,214 \\
JorgeN & 10,101 & 4,914 & 2,056 & $0,040^{*}$ \\
JulioL & 6,580 & 4,914 & 1,339 & 0,181 \\
RobertoS & 4,101 & 5,561 & 0,737 & 0,461 \\
RodrigoL & 9,534 & 3,631 & 2,626 & $0,009 * *$ \\
\hline \multicolumn{4}{c}{ Modelo: $1 \mathrm{~lm}(\mathrm{~F} 1 . \mathrm{NORM} \sim$ INFORMANTE, data $=$ h.1.SP.o) }
\end{tabular}

As Tabelas 5 e 6 mostram as estimativas, para as vogais /e/ e /o/, respectivamente, dos migrantes homens da rede 1, em comparação com os paulistanos (valor do intercept). No caso da vogal /e/, o modelo indica que não existe diferença significativa entre a média de F1 dos paulistanos e as médias dos migrantes, assim como foi visto na Tabela 1. Tal resultado aponta para uma acomodação desses sujeitos. Por outro lado, esse mesmo panorama não se observa nas estimativas para a vogal /o/, pois JoaquimS, JorgeN e RodrigoL apresentam médias significativamente diferentes da observada na fala dos paulistanos. Dito de outro modo, significa que esses três migrantes ainda produzem a vogal /o/ com um grau maior de abertura. Essas duas tabelas já mostram, portanto, que o processo de acomodação dialetal parece ocorrer de maneira distinta entre as vogais e que, além disso, indivíduos de uma mesma rede podem apresentar taxas diferentes de acomodação.

Tabela 7: Estimativas (em Hz) de valores de F1 normalizados para vogal /e/ pretônica dos homens da rede $2(\mathrm{~N}=1178)$

\begin{tabular}{lrrrr}
\hline & Estimativa & Erro padrão & Valor de $\boldsymbol{t}$ & Significância (p) \\
\hline (Intercept) & 430,416 & 2,206 & 195,137 & $<2 \mathrm{e}-16^{* * *}$ \\
AlexandreS & 1,168 & 4,063 & 0,287 & 0,774 \\
EmersonS & $-4,005$ & 3,479 & $-1,151$ & 0,250 \\
JoãoS & 9,942 & 3,274 & 3,036 & $0,002 * *$ \\
LeandroB & $-5,807$ & 3,702 & $-1,569$ & 0,117 \\
LucasB & 4,507 & 3,158 & 1,427 & 0,154 \\
PedroB & $-6,514$ & 3,447 & $-1,890$ & 0,059 \\
ReinaldoB & 1,327 & 3,037 & 0,437 & 0,662 \\
\hline \multicolumn{5}{c}{ Modelo: $\operatorname{lm}(\mathrm{F} 1$. NORM $\sim$ INFORMANTE, data $=$ h.2.SP.e) }
\end{tabular}


Tabela 8: Estimativas (em Hz) de valores de F1 normalizados para vogal /o/ pretônica dos homens da rede $2(\mathrm{~N}=688)$

\begin{tabular}{lrrrr}
\hline & Estimativa & Erro padrão & Valor de $\boldsymbol{t}$ & Significância $(\boldsymbol{p})$ \\
\hline (Intercept) & 439,108 & 2,715 & 161,739 & $<2 \mathrm{e}-16^{* * *}$ \\
AlexandreS & 12,173 & 6,693 & 1,819 & $0,069$. \\
EmersonS & 14,909 & 6,095 & 2,446 & $0,015^{*}$ \\
JoãoS & 12,417 & 4,443 & 2,795 & $0,005^{* *}$ \\
LeandroB & 29,508 & 5,865 & 5,031 & $<0,001^{* * *}$ \\
LucasB & 6,590 & 5,341 & 1,234 & 0,218 \\
PedroB & 19,987 & 4,820 & 4,146 & $<0,001^{* * *}$ \\
ReinaldoB & 14,623 & 5,341 & 2,738 & $0,006^{* *}$ \\
\hline \multicolumn{5}{c}{ Modelo: Im (F1.NORM $\sim$ INFORMANTE, data $=$ h.2.SP.o) }
\end{tabular}

Por sua vez, as Tabelas 7 e 8 mostram as estimativas dos migrantes homens da rede 2 em comparação com os paulistanos (valor do intercept). Na Tabela 7, referente à vogal /e/, apenas JoãoS apresenta uma média significativamente diferente daquela dos paulistanos. No entanto, em relação a /o/, dos 7 sujeitos da rede 2, apenas 2 não têm estimativas significativamente diferentes dos paulistanos. Como visto nos resultados gerais (Tabelas 3 e 4), e com o acréscimo dessas estimativas individuais, observa-se que as taxas de acomodação são diferentes a depender da vogal e do sujeito.

\section{Considerações finais}

Como foi visto, os modelos sinalizam que existe variação dentro de uma mesma rede: parece que alguns migrantes se acomodaram mais, enquanto outros não (vê-se, por exemplo, os casos de JoãoS e AlexandreS). Notou-se também que a acomodação dialetal ocorre de jeitos distintos entre as vogais: o sujeito que tem uma vogal /e/ mais fechada pode apresentar uma vogal /o/ mais aberta e vice-versa (o que, de fato, ocorre com praticamente todos os indivíduos da rede 2). Tal resultado também foi encontrado por Oushiro (2016), com os migrantes paraibanos residentes nas cidades de São Paulo e do Rio de Janeiro.

A respeito da variação entre os indivíduos, fica evidente que mais variáveis devem ser incluídas nas análises: idade de chegada em São Paulo e tempo de residência na nova localidade, por exemplo, podem ser importantes para compreender esse processo (e são fatores analisados em outras pesquisas sobre o assunto, como em Marques (2006) e em Chacon (2012)). No entanto, já é possível visualizar que migrantes com menos tempo em São Paulo estão mais acomodados do que outros que estão há mais tempo. Aqui cabe, então, refletir sobre o conceito de identidade: é possível estabelecer uma relação entre a identidade do falante e o processo de acomodação? Pois, por qual motivo um migrante que está há mais de 35 anos em São Paulo, como o caso de JoaquimS, da rede 1, ainda produz vogais mais abertas do que os paulistanos? Ou, ainda, por que um sujeito que migrou há menos de 20 anos, como AlexandreS, já apresenta médias mais próximas da média dos paulistanos?

Os próximos passos dessa pesquisa, portanto, se voltarão para a análise dessas questões, de modo que a proporção de vida em São Paulo e aspectos identitários de cada migrante serão averiguados com o intuito de buscar alguma correlação com os padrões variáveis de cada um dos indivíduos. 


\section{REFERÊNCIAS}

BARBOSA, P.; MADUREIRA, S. Manual de fonética acústica experimental: aplicações a dados do português. São Paulo: Cortez, 2015.

BOERSMA, P.; WEENINK, D. Praat: doing phonetics by computer. Disponível em: $<$ http://www.fon.hum.uva.nl/praat/>. Acesso em: 27 ago. 2017.

BORTONI-RICARDO, S. M. Do campo para a cidade: estudo sociolinguístico de migração e redes sociais. São Paulo: Parábola Editorial, 2011 [1985].

CHACON, K. A. Contato dialetal: análise do falar paulista em João Pessoa. 2012. 118 f. Dissertação (Mestrado em Linguística) - Centro de Ciências Humanas, Letras e Artes, Universidade Federal da Paraíba, João Pessoa, 2012.

ECKERT, P. "Three Waves of Variation Study: The emergence of Meaning in the Study of Sociolinguistic Variation". Annual Review of Anthropology, 41, p. 87-100, 2012.

FREITAG, R. M. K. Banco de dados Falares Sergipanos. Working Papers em Linguística, Santa Catarina, v. 14, n. 2, p. 156-164, 2013.

GUY, G. Introdução à análise quantitativa da variação linguística. In: GUY, G.; ZILLES, A. Sociolinguística Quantitativa: Instrumental de Análise. São Paulo: Parábola Editorial, 2007. p. 19-46.

LABOV, W. Padrões sociolinguísticos. Tradução de Marcos Bagno, Maria Marta Pereira Scherre e Caroline Rodrigues Cardoso. São Paulo: Parábola Editorial, 2008 [1972].

LOBANOV, B. M. Classification of Russian vowels spoken by different listeners. J. Acoust. Soc. Am., v. 49, p. 606-608, 1971.

MARQUES, S. M. O. As vogais médias pretônicas em situação de contato dialetal. 2006. 161 f. Tese (Doutorado em Linguística) - Faculdade de Letras, Universidade Federal do Rio de Janeiro, Rio de Janeiro, 2006.

MENDES, R. B.; OUSHIRO, L. O paulistano no mapa sociolinguístico brasileiro. Alfa, v. 56, n. 3, p. 973-1001, 2012.

MILROY, L. Language and social networks. 2. ed. Oxford: Blackwell, 1987 [1980].

MILROY, L.; LLAMAS, C. Social networks. In: CHAMBERS, J. K.; TRUDGILL, P.; SCHILLING-ESTES, N. (Eds.). The Handbook of Language and Change. Blackwell: Malden, MA. 2. ed. 2013 [2002]. p. 409-427.

MOTA, J. Vogais antes do acento em Ribeirópolis - SE. 2. v. 1979. 287 f. Dissertação (Mestrado em Língua Portuguesa) - Instituto de Letras, Universidade Federal da Bahia, Salvador, 1979.

NASCENTES, A. O linguajar carioca. Rio de Janeiro: Organização Simões, 1953 [1922].

OUSHIRO, L. A acomodação dialetal e a estabilidade de padrões sociolinguísticos na fala adulta. 2016. 84 f. Relatório Científico (Pós-doutorado em Linguística) - Faculdade de Letras, Universidade Federal do Rio de Janeiro, Rio de Janeiro, 2016. 
R CORE TEAM. R: A language and environment for statistical computing. R Foundation for Statistical Computing, Vienna, Austria, 2017. Disponível em: <http://www.Rproject.org/>. Acesso em: 27 ago. 2017.

TRUDGILL, P. Dialects in contact. Oxford: Blackwell, 1986.

Recebido em: 27/08/2017

Aprovado em: 01/08/2018 